\title{
Article \\ Safety Assessment Model for Dangerous Goods Transport by Air Carrier
}

\author{
Hongli Zhao ${ }^{1,2, *(\mathbb{D})}$, Ning Zhang ${ }^{1,3}$ and Yu Guan ${ }^{4}$ \\ School of Economy and Management, Beihang University, Beijing 100191, China; nzhang@buaa.edu.cn \\ Civil Aviation Management Institute of China, Beijing 100102, China \\ 3 Collaborative Innovation Center for Aviation Economy Development, Zhengzhou University of aeronautics, \\ Zhengzhou 450015, China \\ 4 China International Engineering Consulting Corporation, Beijing 100048, China; gy_buaa@163.com \\ * Correspondence: zhaohongli@buaa.edu.cn; Tel.: +86-10-5825-0589
}

Received: 15 March 2018; Accepted: 20 April 2018; Published: 24 April 2018

\begin{abstract}
The safety of dangerous goods transport by air is directly related to human health and environmental pollution. This paper investigates a model to evaluate the safety performance of the transport of dangerous goods by air carriers. Based on a literature review, international regulations related to dangerous goods air transportation, and expert opinions, this paper identifies an assessment factor system with five drivers: organization/regulations, equipment/facilities, operations, emergency, and training. A hybrid evaluation method of a joint analytical hierarchy process and entropy weight is used to determine the importance of each factor and driver. The results suggest that the regulation of dangerous goods acceptance, sufficient equipment/facilities, and the condition of the equipment/facilities are the most important factors affecting the safety performance of dangerous goods transportation by air. An empirical study reveals that the proposed model is stable and reliable; thus, the model can guide resource allocation for air carriers to improve safety management of dangerous goods transportation.
\end{abstract}

Keywords: air transportation; assessment model; analytic hierarchy process (AHP); entropy weight; dangerous goods

\section{Introduction}

The safe transport of dangerous goods is of paramount importance to the government and enterprises in any country. The type and quantity of dangerous goods transported via air continue to increase due to new technologies and the use of new types of hazardous materials [1]. Dangerous goods include explosives, flammables, oxidizing substances, toxins, radioactive materials, and corrosive materials. If these hazardous substances are not properly handled, risks such as leakage, fire, or explosions may lead to air accidents or incidents, threatening the safety of air transport. These consequences may cause personal injury, property damage, and especially, environmental pollution [2]. For example, on 28 July 2011, a Boeing 747-48EF cargo aircraft owned by Asiana Airlines traveling from Seoul to Shanghai caught fire and crashed into the sea $107 \mathrm{~km}$ west of the Jeju Island [3]. An investigation of the accident indicated that the cargo aircraft was carrying a total of 58 tons of newly developed electronic products, including mobile phones and lithium batteries, which are classified as dangerous goods [3]. This accident caused two personal deaths, expensive losses of cargo and an aircraft, and sea pollution. The extent of consequences of such incidents depends on the type and quantity of the dangerous goods and the circumstances of the release. The pollution will be more serious if toxic substances, corrosive materials, or radioactive materials are being carried and then released. Although serious accidents resulting in heavy pollution during the air transportation 
of dangerous goods have not occurred in recent years, each company that handles dangerous goods, including air carriers, is at risk of accidents or of other unsafe events that may cause great damage to the economy and peoples' lives as well as to the property and the environment. Therefore, from the perspective of the government and air carriers, ensuring the safety and minimizing the risk and potential losses caused by such incidents is highly important.

Research referring to dangerous goods transportation has addressed different aspects of these problems. Routing choice or road selection have long been areas of interest in the road transport of dangerous goods, aiming to reduce the potential negative environmental and public health impacts [4-6]. The safety analysis and a risk assessment approach comprise the other focuses of the research on road tunnels, railways, and sea transport of dangerous goods [7-11]. The methodology used in risk-related research can be classified as qualitative, quantitative, or a combination thereof. Qualitative approaches mainly summarize risk hazard identification from historical data of accidents, incidents, and unsafe events to identify control measures for reducing accident rates [8,9], relying on sharp insight and experience. Some studies have proposed specific mathematical formulas to calculate the accident rate, damage rate, release rate, and concentration level of released dangerous goods in railway transportation [10,12], but no empirical application currently exists. In terms of the combined qualitative and quantitative approach, a popular tool is the risk matrix, which couples hazard severity levels with likelihood levels to determine a cumulative risk level based on an expert's score on each risk factor $[13,14]$. Another representative decision-making method combining qualitative and quantitative techniques is the analytic hierarchy process (AHP). Different types of risk factors are identified hierarchically in the first step via qualitative analysis and then prioritized in order of importance as calculated using a quantitative method [11,14,15]. The advantage of AHP lies in the use of expert experience to quantify the relative importance of factors at different levels. A disadvantage is that the factor weights are easily affected by expert subjectivity.

Prior studies have highlighted the importance of safety analysis or risk assessment when transporting dangerous goods by road, railway, and sea; however, few scholars have discussed these topics with respect to air transport. No research appears to have focused specifically on the safety evaluation or risk assessment of dangerous goods transported by air. Hsu et al. [14] established 14 indicators and established a risk matrix to evaluate the operational safety of dangerous goods transported via air using fuzzy AHP in the Taiwan region. Chang et al. [15] identified 17 risk factors using expert interviews and prioritized the order of management problems associated with air transport of dangerous goods using AHP in the Taiwan region. However, both studies were limited to Taiwan. Furthermore, the risk factors were identified from an industry development perspective, including policies and regulations, safety audits and supervision, cargo agents, air police stations, and customs airline personnel; only three indices were geared toward air carriers, which is hardly sufficient to guide the management of dangerous goods in such settings. Research in this field began in China in 2000, and over 10 papers on risk analysis have been published up to this point, but few have dealt with air carriers based on the evaluation methodology. Du [16] established 10 indices based on personnel, equipment, environment, and management to evaluate the safety of dangerous goods transport activities among air carriers, but these factors lacked the necessary detail to guide air carriers in improving their management of dangerous goods transport. A vulnerability assessment of a ground emergency system pertaining to the air transport of dangerous goods was studied, including emergency system construction and system implementation vulnerability [17]; unfortunately, the research did not extend to other activities. Therefore, studies of risk assessment in dangerous goods transport focusing on air carriers are needed. The present study seeks to fill this gap.

An increasing volume of hazardous materials has been transported via air in China in recent years. By 2016, 26 out of 59 domestic airlines (44\%) held permits for the air transport of dangerous goods as cargo [18]. Dangerous goods transported by air can be found in air freights as well as items carried by passengers or in checked baggage. Statistics show that the risk of unsafe incidents caused by luggage is larger than that caused by cargo [19]. The safety of dangerous goods air transportation is 
an unavoidable and pressing issue for airlines. Safety always comes first. If an air carrier encounters an unacceptable risk, no passenger will be willing to board its flight and the sustainable development of the airline will likely be questionable. If the air transportation industry is exposed to many enduring potential risks of dangerous goods, then the corresponding negative impacts on the economy, society, and environment cannot be ignored.

To ensure and improve the safety level, a safety management system (SMS) was introduced and has become increasingly popular among governments and air enterprises [20]. Beginning in 2015, the International Civil Aviation Organization (ICAO) required dangerous goods safety management to include air carrier SMS [21]. The core of the SMS is risk management, and the most crucial component of risk management is the identification of safety factors to monitor potential risks prior to accidents and incidents, which is the foundation of control measure development.

In the previous literature, accident or fatality data were often investigated and used to measure risk and/or safety of dangerous goods transport by road, railway, and sea [6-9]. However, from a sustainability perspective, safety refers to preventing historical accidents and incidents from occurring again while ensuring a timely response to such events. It is more important to take corrective action to prevent future errors by emphasizing proactive safety measures, including adequate funds, resources, and manpower [22]. This study aims to assess the proactive safety performance of dangerous goods air carriers to prevent accidents before they occur. The overall goals of this study were to establish a model to assess the safety performance of air transport companies. The proposed model includes two key issues: factors affecting the safety sustainability of air transport enterprises and how to assign weights to these factors. The main objectives of this study are as follows:

- To identify and categorize the main contributing factors in dangerous goods transport that affect the safety and sustainability of air enterprises.

- To assign weights to these factors using a reasonable method.

- To test the model stability through an empirical study.

\section{Research Method}

The risk management process is used as a reference in this paper to establish the safety assessment model for air transport of dangerous goods. The first step of the risk management process is the identification of all potential risks. The next step is the assessment of identified risks to select suitable and effective safety control measures leading to risk reduction. Thus, risk factor identification and assessment are the most vital components of the entire risk management process.

The framework of this research process is shown in Figure 1. Several methods were used to achieve the research objectives. To compile a comprehensive list of risk factors, interviews with dangerous goods air transportation experts, using the Delphi method, were conducted to validate safety factors identified based on a literature review and to explore additional factors. In the assessment model, weight assignment is an important part of the evaluation result. At present, subjective and objective assignment methods constitute the major approaches. In the second step, to measure the weight of each identified safety factor, a mixed analysis method combining the AHP method and the entropy method was applied. The former involves expert-based weight attribution and the latter can compensate for the deficiencies of subjective opinion to some extent. The assessment model was established by calculation and analysis. Finally, an empirical study was used to apply a fuzzy synthetic evaluation (FSE) method to the model, and the combined method of the weight assignment proved to be stable. 


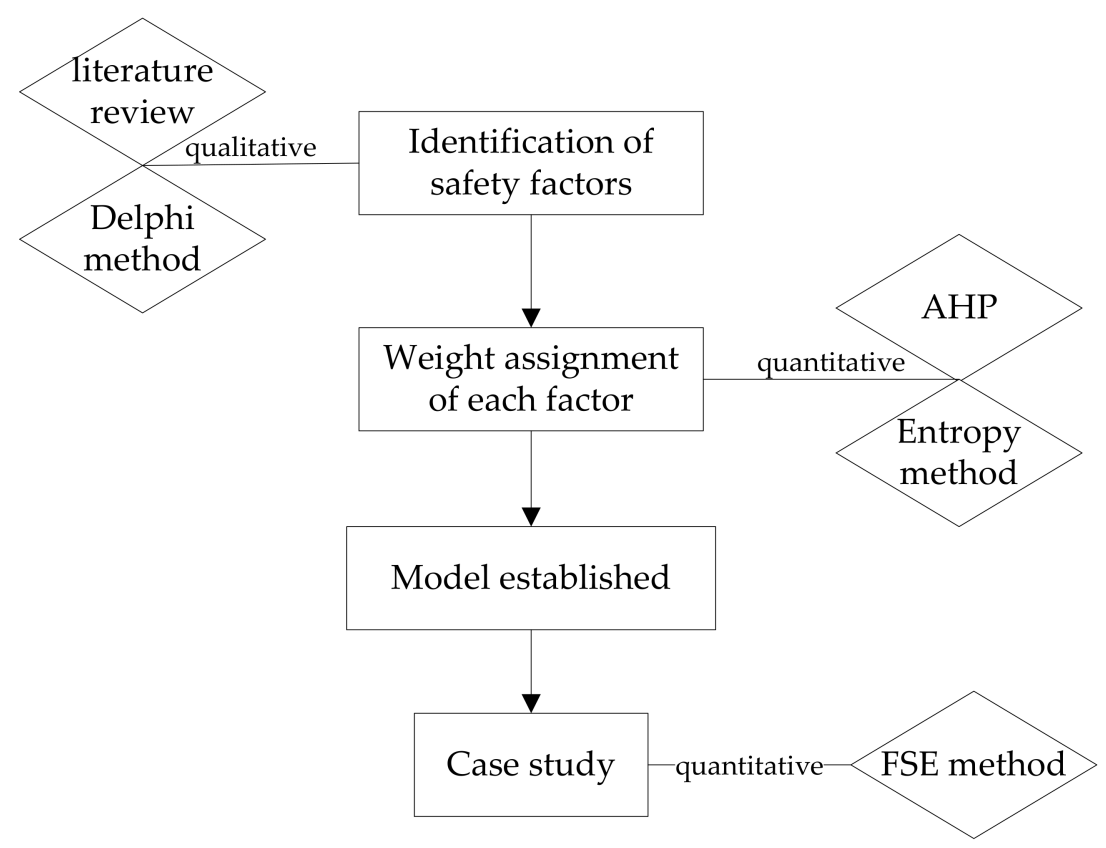

Figure 1. The research method framework.

\section{Model Established}

\subsection{Identification of Safety Factors}

Establishing factors for air carrier safety assessment is a critical feature of this study and provides a foundation for subsequent research. A literature review and expert interviews were conducted for this paper. The literature review surveyed previous research on dangerous goods transported by road, railway, sea, and air. A universal definition of safety research on a metro railway was used for reference, which outlined six preliminary categories composed of human factors, facilities, and management actions [23]. Though that research was aimed at the safety management of metro enterprises rather than dangerous goods transport, some attributes are transferable to dangerous goods transportation via air; certain factors, such as investment and infrastructure, are essential to any business seeking to ensure safety.

Dangerous goods air transport must be carried out according to regulations, including specific operation and training requirements. These include Annex 18 to the Convention on International Civil Aviation (Chicago Convention), The Safe Transport of Dangerous Goods by Air [24], which outlines the responsibilities of dangerous goods operators, including operations, information, and training; and Technical Instructions for the Safe Transport of Dangerous Goods by Air (Doc 9284) [25], issued by the ICAO, which stipulates specific operational responsibilities for airline operators, including stowing, segregation, and documentation. These regulations are legal requirements for member states, and China is no exception.

Based on the extant literature and international regulations, 19 factors influencing the safety performance of air transport of dangerous goods were collected. The list of factors was then examined by 15 experts on dangerous goods air transportation. The professionals came from enterprises, government, and research institutes, and all are knowledgeable in the field of air safety with at least 10 years of experience. The detail information of all the 15 experts is listed in Table 1. 
Table 1. The detail information of the 15 experts.

\begin{tabular}{ccc}
\hline Items & Description & Number \\
\hline \multirow{2}{*}{ Gender } & Male & 7 \\
& Female & 8 \\
\hline \multirow{2}{*}{ Age } & 36-45 years old & 7 \\
& 46-55 years old & 8 \\
\hline \multirow{2}{*}{ Education } & Bachelor degree & 9 \\
& Graduate and above & 6 \\
\hline \multirow{2}{*}{ Years of experience } & 10-15 years & 4 \\
& 15-20 years & 8 \\
& over 20 years & 3 \\
\hline \multirow{2}{*}{ Service institution } & enterprises & 8 \\
& government & 2 \\
& research institutes & 5 \\
\hline
\end{tabular}

After reviewing the list, some experts suggested adding the factor of "quality control of outsourcing" to the index set because some air carriers outsource dangerous goods business to ground handling agents; hence, a good quality control program is needed to ensure the outsourcer party complies with all safety requirements of the carrier. Then, the list of factors was updated and re-distributed to the 15 experts, who agreed that all factors derived from the literature, regulations, and expert opinion were reasonable and important. The final 20 factors are presented in Table 2, grouped into five dimensions based on their properties and attributes: organization/regulations, equipment/facilities, operations, emergency, and training. Table 2 also provides an explanation of each factor and corresponding references.

Table 2. The safety factors of dangerous goods air carriers.

\begin{tabular}{|c|c|c|}
\hline Drivers & Factors & Explanation \\
\hline \multirow{6}{*}{$\begin{array}{l}\text { Organization and } \\
\text { regulations (E1) }\end{array}$} & $\begin{array}{l}\text { Organizational } \\
\text { structure }\left(\mathrm{E}_{11}\right)\end{array}$ & $\begin{array}{l}\text { A good organizational and managerial structure delineates clear } \\
\text { responsibilities and a reasonable division of labor [16]. }\end{array}$ \\
\hline & $\begin{array}{l}\text { Quality control of } \\
\text { outsourcing }\left(E_{12}\right)\end{array}$ & $\begin{array}{l}\text { The quality control system is effective if dangerous goods business } \\
\text { is outsourced [Expert opinion]. }\end{array}$ \\
\hline & $\begin{array}{l}\text { Communication } \\
\text { and coordination } \\
\left(E_{13}\right)\end{array}$ & $\begin{array}{l}\text { Smooth and effective communication and coordination between } \\
\text { company departments are essential for daily work }[8,16] \text {. }\end{array}$ \\
\hline & $\begin{array}{l}\text { Safety investment } \\
\left(\mathrm{E}_{14}\right)\end{array}$ & $\begin{array}{l}\text { Safety investment is essential funding that ensures safe operation of } \\
\text { dangerous goods, such as by introducing new technology, training, } \\
\text { safety incentives, or other activities [23]. }\end{array}$ \\
\hline & $\begin{array}{l}\text { Rules and } \\
\text { regulations }\left(\mathrm{E}_{15}\right)\end{array}$ & $\begin{array}{l}\text { Rules and regulations delineate clear responsibilities for staff, } \\
\text { thereby improving safety overall }[15,16] \text {. }\end{array}$ \\
\hline & $\begin{array}{l}\text { Self-supervision } \\
\left(\mathrm{E}_{16}\right)\end{array}$ & $\begin{array}{l}\text { A clear dangerous goods self-supervision and inspection system } \\
\text { with well-defined responsibilities is necessary for proper } \\
\text { implementation }[16,24] \text {. }\end{array}$ \\
\hline \multirow{3}{*}{$\begin{array}{l}\text { Equipment and } \\
\text { facilities (E2) }\end{array}$} & $\begin{array}{l}\text { Sufficient } \\
\text { equipment/facilities } \\
\left(E_{21}\right)\end{array}$ & $\begin{array}{l}\text { Accidents are likely to occur if equipment and facilities are } \\
\text { inadequate }[8,14,15] .\end{array}$ \\
\hline & $\begin{array}{l}\text { Equipment/facilities } \\
\text { conditions }\left(\mathrm{E}_{22}\right)\end{array}$ & $\begin{array}{l}\text { The condition of equipment and facilities depends on service times } \\
\text { and maintenance }[16,23] \text {. }\end{array}$ \\
\hline & $\begin{array}{l}\text { Equipment/facilities } \\
\text { performance }\left(\mathrm{E}_{23}\right)\end{array}$ & $\begin{array}{l}\text { Equipment and facilities should be reliable, and advanced } \\
\text { technology should be adopted to meet increasing freight volume } \\
{[16,23] \text {. }}\end{array}$ \\
\hline
\end{tabular}


Table 2. Cont.

\begin{tabular}{|c|c|c|}
\hline Drivers & Factors & Explanation \\
\hline \multirow{5}{*}{ Operations (E3) } & $\begin{array}{l}\text { Luggage safety } \\
\text { operations }\left(E_{31}\right)\end{array}$ & $\begin{array}{l}\text { Responsibilities such as sharing information with passengers and } \\
\text { pre-checking and receiving luggage must be in place and performed } \\
\text { properly }[24,25] \text {. }\end{array}$ \\
\hline & $\begin{array}{l}\text { Ordinary cargo } \\
\text { safety operations } \\
\left(E_{32}\right)\end{array}$ & $\begin{array}{l}\text { Responsibilities such as sharing information with shippers and } \\
\text { pre-checking and receiving cargo must be in place and performed } \\
\text { properly }[24,25] \text {. }\end{array}$ \\
\hline & $\begin{array}{l}\text { Dangerous goods } \\
\text { acceptance }\left(E_{33}\right)\end{array}$ & $\begin{array}{l}\text { Checking and receipt of dangerous goods must be consistent, and } \\
\text { all transport documents, packaging, and so forth must comply with } \\
\text { regulations }[24,25] \text {. }\end{array}$ \\
\hline & $\begin{array}{l}\text { Dangerous goods } \\
\text { storage }\left(E_{34}\right)\end{array}$ & $\begin{array}{l}\text { The storage and stacking of dangerous goods must conform to } \\
\text { regulatory requirements }[24,25] \text {. }\end{array}$ \\
\hline & $\begin{array}{l}\text { Dangerous goods } \\
\text { loading }\left(\mathrm{E}_{35}\right)\end{array}$ & $\begin{array}{l}\text { Dangerous goods allocation, aircraft commander notice, apron } \\
\text { loading, and other ground supports must conform to regulatory } \\
\text { requirements }[14,24,25] \text {. }\end{array}$ \\
\hline \multirow{3}{*}{ Emergency (E4) } & $\begin{array}{l}\text { Emergency } \\
\text { management plan } \\
\left(\mathrm{E}_{41}\right)\end{array}$ & $\begin{array}{l}\text { The emergency management plan is an action guide to minimize } \\
\text { potential event damage [17]. }\end{array}$ \\
\hline & $\begin{array}{l}\text { Emergency-handling } \\
\text { measures }\left(E_{42}\right)\end{array}$ & $\begin{array}{l}\text { Emergency-handling personnel and equipment must be adequate; } \\
\text { efficient and timely actions contribute to safety [17]. }\end{array}$ \\
\hline & $\begin{array}{l}\text { Emergency drilling } \\
\text { plan }\left(E_{43}\right)\end{array}$ & $\begin{array}{l}\text { The emergency drilling plan should be complete and conducted } \\
\text { regularly. Summarizing problems after drilling will help to improve } \\
\text { safety [17]. }\end{array}$ \\
\hline \multirow{3}{*}{ Training (E5) } & $\begin{array}{l}\text { Training } \\
\text { organization }\left(E_{51}\right)\end{array}$ & $\begin{array}{l}\text { A specific department should be responsible for organizing staff } \\
\text { training to improve operational capabilities }[24,25] \text {. }\end{array}$ \\
\hline & $\begin{array}{l}\text { Training program } \\
\left(\mathrm{E}_{52}\right)\end{array}$ & $\begin{array}{l}\text { The dangerous goods training program should be up-to-date and } \\
\text { compliant with ICAO requirements }[15,24,25] \text {. }\end{array}$ \\
\hline & $\begin{array}{l}\text { Training quality } \\
\left.\text { control ( } \mathrm{E}_{53}\right)\end{array}$ & $\begin{array}{l}\text { The training quality depends on the instructor, training method, } \\
\text { training environment and location, and so forth }[16,24,25] \text {. }\end{array}$ \\
\hline
\end{tabular}

\subsection{Weight Assignment}

The safety factors discussed in the previous section may not equally affect the safety of dangerous goods air carriers. A method of weight assignment must, therefore, be introduced to reflect respective contributions to each safety factor and driver. A hybrid evaluation method based on AHP and entropy weight is proposed in this study.

$\mathrm{AHP}$ is a structured technique for organizing and analyzing complex decisions. It provides a comprehensive and rational framework for group decision making and is widely used around the world [26]. However, the disadvantage of AHP is that it is influenced easily by expert knowledge and experience or the preferences of decision makers. The entropy method is mainly based on the correlation among the indicators, using a certain mathematical model, to calculate the index weights. The advantage is that it fully taps into the information implied in the raw data and the evaluation results are backed by a strong mathematical theory [27]. However, it ignores the knowledge and experience of decision makers, and sometimes, the weight obtained from them may not match the actual importance.

Given the advantages and disadvantages of these two methods, this study attempts to combine AHP and entropy by adopting the latter to complement the functions of the former. The two methods can thus overcome their shortcomings and make the results more accurate. Notably, this research is not the first to combine the entropy weights with AHP to determine index weight. The entropy method first appeared in thermodynamics and was incorporated into information theory by American mathematician Shannon [28]. The earliest application of the entropy weighting method in conjunction with AHP was a study of ship investment decision making [29]. Nowadays, the AHP-entropy method 
has been known and used in the assessment of various industries, including the safety assessment of food-waste feed [27], the safety evaluation of smart grids [30], the risk assessment in banks [31], and in community sustainability assessments [32]. These studies demonstrated that this integrated method is scientific and effective.

\subsubsection{Steps of AHP}

The basic process to obtain the weights is detailed below (adapted from Reference [33]):

Step 1: Construct a set of relative weight matrices (RWMs).

This paper uses a 1-9-point scale to score the relative importance of each driver and factor individually. For instance, if driver E1 and E2 are measured, and E1 is 5 times more important than E2 to the goal of safely transporting dangerous goods by air carriers, then the relative weight of E1 to E2 is denoted as 5; if E2 is 5 times more important than E1, the relative weight of E1 to E2 is denoted as $1 / 5$. As illustrated above, each driver is assigned a global priority. This process is also used to weight the priorities on the upper level (its driver) for each factor.

Step 2: Hierarchical ordering.

After establishing the RWMs, the maximum eigenvalues and corresponding eigenvectors of each RWM can be calculated. Various hierarchy factors are ordered by their importance relative to other factors from the previous hierarchy (that is, hierarchical ordering).

$$
E \times h=\lambda_{\max } \times h, \sum_{i=1}^{n} h_{i}=1
$$

where $n$ is the size of the matrix, $E=\left(e_{i j}\right)_{n \times n}$ is the RWM, $\lambda_{\max }$ is the maximum eigenvalue of matrix $E$, and $h$ denotes the eigenvectors of $E$.

Step 3: Examine the consistency of the hierarchy.

The consistency index $(C I)$ is used to determine the consistency of the hierarchy. It is calculated as follows:

$$
C I=\frac{\left(\lambda_{\max }-n\right)}{(n-1)}
$$

Then, the random consistency ratio $(C R)$ is obtained from

$$
C R=\frac{C I}{R I}
$$

The $R I$ is the average random consistency index. The value of $R I$ for different matrix orders appears in Table 3.

Table 3. The average random consistency index of the 1-10 matrices.

\begin{tabular}{ccccccccccc}
\hline $\boldsymbol{n}$ & $\mathbf{1}$ & $\mathbf{2}$ & $\mathbf{3}$ & $\mathbf{4}$ & $\mathbf{5}$ & $\mathbf{6}$ & $\mathbf{7}$ & $\mathbf{8}$ & $\mathbf{9}$ & $\mathbf{1 0}$ \\
\hline$R I$ & 0 & 0 & 0.58 & 0.90 & 1.12 & 1.24 & 1.32 & 1.41 & 1.45 & 1.49 \\
\hline
\end{tabular}

When the $C R$ is less than 0.1 , the weight coefficient distribution is reasonable and the matrix is considered consistent; otherwise, the RWM must be revised and the weight coefficient should be re-distributed.

\subsubsection{Steps of Entropy Weight}

The entropy method can measure the degree of disorder in a system. When the indicator provides more useful information, the difference in values among the evaluated objects on the same indicator is high and the entropy is small; thus, the weight of the selected indicator should be set correspondingly high. On the contrary, if the difference is small and the entropy is high, then the relative weight should 
be smaller [34]. The entropy weight method can reduce the impact of the subjective arbitrariness in the empowerment, making the evaluation result more objective. The steps of the entropy weight method are as follows:

Step 1: Normalize the elements of $E=\left(e_{i j}\right)_{n \times n}$ RWM and obtain the standard matrix $F=\left(f_{i j}\right)_{n \times n}$

$$
f_{i j}=\frac{e_{i j}}{\sum_{j=1}^{n} e_{i j}}
$$

Step 2: Calculate the entropy $G_{j}$, variation coefficient $K_{j}$, and weight $L_{j}$ of each index:

$$
\begin{gathered}
G_{j}=-\frac{1}{\ln n} \sum_{i=1}^{n} f_{i j} \ln f_{i j} \\
K_{j}=1-G_{j} \\
L_{j}=\frac{K_{j}}{\sum_{j=1}^{n} K_{j}}
\end{gathered}
$$

Step 3: Use the entropy weight $L_{j}$ of the $j^{\text {th }}$ index to revise the weight vector $h_{j}$ obtained via AHP to derive the comprehensive weight of the $j^{\text {th }}$ evaluation index $W_{j}$ :

$$
W_{j}=\frac{L_{j} h_{j}}{\sum_{j=1}^{n} L_{j} h_{j}}
$$

When using the AHP-entropy method to evaluate the safety vulnerability of dangerous goods air carriers, the weights are calculated twice: AHP gives subjective results and the entropy weight provides an objective evaluation. This integrated method ensures the scientific reliability of the weight assigned to each factor that is combined with expert experience and the original objective data.

\subsubsection{Calculation}

The 15 experts were invited to determine the contribution of each safety factor to each driver using AHP. These experts included scholars and government administrators, the latter of whom possessed greater authority in dangerous goods air transportation but did not have sufficient understanding of AHP. To comprehensively assess this scoring method, we distributed e-mail questionnaires to obtain the factor weights and the respondents then provided an oral explanation of the scoring method by telephone.

Five drivers of organization/regulations (E1), equipment/facilities (E2), operations (E3), emergency (E4), and training (E5) were placed at the criteria level. The sub-criteria level was composed of 20 safety factors. Each of the 15 experts provided six RWMs containing five matrices at the sub-criteria level and one matrix at the criteria level; a total of 90 RWMs were collected. Then, the arithmetical average values of the 15 experts' RWMs were calculated to obtain six final RWMs to proceed to step 2 of the AHP method. Taking the 15 RWMs of the criteria level (five drivers) as an example, the average results are shown in Table 4.

Table 4. The relative weight matrix of the five drivers.

\begin{tabular}{cccccc}
\hline Drivers & E1 & E2 & E3 & E4 & E5 \\
\hline E1 & 1 & 2.391111 & 2.055238 & 2.976296 & 2.344444 \\
E2 & 0.418216 & 1 & 2.082222 & 2.896296 & 2.211111 \\
E3 & 0.486562 & 0.480256 & 1 & 2.874074 & 2.34 \\
E4 & 0.335988 & 0.345269 & 0.347938 & 1 & 1.516296 \\
E5 & 0.42654 & 0.452261 & 0.42735 & 0.659502 & 1 \\
\hline
\end{tabular}


Next, we calculated the maximum eigenvalue $\lambda_{\max }=5.2269$ and obtained the eigenvector. $h=(0.3597,0.2501,0.1921,0.0981)^{T}$. The $C I$ equaled

$$
C I=\frac{\lambda_{\max }-n}{n-1}=\frac{5.2269-5}{5-1}=0.0567
$$

As shown in Table 3, when $n=5, R I=1.12$, from which we determined that $C R=\frac{C I}{R I}<0.1$. Therefore, the consistency of this RWM is satisfactory, indicating that the distribution of weights is reasonable. Next, we calculated the entropy, variation coefficient, entropy weight, and comprehensive weight according to Formulas (4)-(8), constructing Table 5:

Table 5. The weight results of the five drivers.

\begin{tabular}{cccccc}
\hline Drivers & AHP Weight & Entropy & Variation Coefficient & Entropy Weight & Comprehensive Weight \\
\hline E1 & 0.3597 & 0.994834 & 0.005166 & 0.09836 & 0.188832 \\
E2 & 0.2501 & 0.988141 & 0.011859 & 0.225782 & 0.301383 \\
E3 & 0.1921 & 0.983953 & 0.016047 & 0.305511 & 0.313234 \\
E4 & 0.1 & 0.986302 & 0.013698 & 0.260785 & 0.139187 \\
E5 & 0.0981 & 0.994245 & 0.005755 & 0.109562 & 0.057365 \\
\hline
\end{tabular}

Similarly, the weight at the sub-criteria level was obtained by the AHP method and revised using the entropy method. All the $C R$ values shown in Table 6 are less than 0.1, suggesting that all RWMs were sufficiently consistent.

Table 6. The consistency check of the five RWMs of the 20 factors.

\begin{tabular}{ccccc}
\hline Factor Matrix & $\boldsymbol{\lambda}_{\max }$ & $\boldsymbol{C I}$ & $\boldsymbol{R I}$ & $\boldsymbol{C R}$ \\
\hline $\mathrm{E}_{11} \sim \mathrm{E}_{16}$ & 6.2282 & 0.0456 & 1.24 & 0.0368 \\
$\mathrm{E}_{21} \sim \mathrm{E}_{23}$ & 3.0689 & 0.0344 & 0.58 & 0.0594 \\
$\mathrm{E}_{31} \sim \mathrm{E}_{35}$ & 5.2511 & 0.0628 & 1.12 & 0.0561 \\
$\mathrm{E}_{41} \sim \mathrm{E}_{43}$ & 3.0642 & 0.0321 & 0.58 & 0.0553 \\
$\mathrm{E}_{51} \sim \mathrm{E}_{53}$ & 3.034 & 0.017 & 0.58 & 0.0293 \\
\hline
\end{tabular}

The AHP weight, entropy weight, and comprehensive weight results for each factor are listed in Table 7.

Table 7. The weight results of the 20 factors.

\begin{tabular}{ccccccc}
\hline \multirow{2}{*}{ Factors } & \multicolumn{2}{c}{ AHP Weight } & \multicolumn{2}{c}{ Entropy Weight } & \multicolumn{2}{c}{ AHP-Entropy Weight } \\
\cline { 2 - 6 } & Local Weight & Global Weight & Local Weight & Global Weight & Local Weight & Global Weight \\
\hline $\mathrm{E}_{11}$ & 0.388 & $7.3 \%$ & 0.113502 & $1.1 \%$ & 0.282154 & $5.3 \%$ \\
$\mathrm{E}_{12}$ & 0.1752 & $3.3 \%$ & 0.21852 & $2.1 \%$ & 0.245289 & $4.6 \%$ \\
$\mathrm{E}_{13}$ & 0.1333 & $2.5 \%$ & 0.217898 & $2.1 \%$ & 0.186095 & $3.5 \%$ \\
$\mathrm{E}_{14}$ & 0.0902 & $1.7 \%$ & 0.185966 & $1.8 \%$ & 0.107471 & $2.0 \%$ \\
$\mathrm{E}_{15}$ & 0.1027 & $1.9 \%$ & 0.161273 & $1.6 \%$ & 0.106117 & $2.0 \%$ \\
$\mathrm{E}_{16}$ & 0.1106 & $2.1 \%$ & 0.102842 & $1.0 \%$ & 0.072875 & $1.4 \%$ \\
$\mathrm{E}_{21}$ & 0.5056 & $15.2 \%$ & 0.369197 & $8.3 \%$ & 0.542323 & $16.3 \%$ \\
$\mathrm{E}_{22}$ & 0.2513 & $7.6 \%$ & 0.510081 & $11.5 \%$ & 0.372413 & $11.2 \%$ \\
$\mathrm{E}_{23}$ & 0.2431 & $7.3 \%$ & 0.120723 & $2.7 \%$ & 0.085264 & $2.6 \%$ \\
$\mathrm{E}_{31}$ & 0.185 & $5.8 \%$ & 0.012719 & $0.4 \%$ & 0.010947 & $0.3 \%$ \\
$\mathrm{E}_{32}$ & 0.2577 & $8.1 \%$ & 0.077747 & $2.4 \%$ & 0.09321 & $2.9 \%$ \\
$\mathrm{E}_{33}$ & 0.3008 & $9.4 \%$ & 0.438008 & $13.4 \%$ & 0.612948 & $19.2 \%$ \\
$\mathrm{E}_{34}$ & 0.1343 & $4.2 \%$ & 0.263426 & $8.0 \%$ & 0.164588 & $5.2 \%$ \\
$\mathrm{E}_{35}$ & 0.1222 & $3.8 \%$ & 0.2081 & $6.4 \%$ & 0.118306 & $3.7 \%$ \\
$\mathrm{E}_{41}$ & 0.5236 & $7.3 \%$ & 0.210608 & $5.5 \%$ & 0.352677 & $4.9 \%$ \\
$\mathrm{E}_{42}$ & 0.333 & $4.6 \%$ & 0.470493 & $12.3 \%$ & 0.50107 & $7.0 \%$ \\
$\mathrm{E}_{43}$ & 0.1434 & $2.0 \%$ & 0.318899 & $8.3 \%$ & 0.146253 & $2.0 \%$ \\
$\mathrm{E}_{51}$ & 0.4824 & $2.8 \%$ & 0.464489 & $5.1 \%$ & 0.640977 & $3.7 \%$ \\
$\mathrm{E}_{52}$ & 0.2182 & $1.3 \%$ & 0.429028 & $4.7 \%$ & 0.267794 & $1.5 \%$ \\
$\mathrm{E}_{53}$ & 0.2995 & $1.7 \%$ & 0.106482 & $1.2 \%$ & 0.091229 & $0.5 \%$ \\
\hline
\end{tabular}




\subsection{Model}

The safety assessment model for dangerous goods transport by air was established after identifying the safety factors and assigning a weight to each. The safety assessment model as described in Table 8 was refined from the results of Tables 2, 5 and 7 . The model can be used to assess the safety level of dangerous goods transport by air for airlines.

Table 8. The safety assessment model for dangerous goods transport by air carriers.

\begin{tabular}{|c|c|c|c|}
\hline 5 Drivers & Weights (W1) & 20 Factors & Weights (W2) \\
\hline \multirow{6}{*}{$\begin{array}{l}\text { Organization and } \\
\text { regulations (E1) }\end{array}$} & \multirow{6}{*}{0.188832} & Organizational structure $\left(\mathrm{E}_{11}\right)$ & 0.282154 \\
\hline & & Quality control of outsourcing $\left(\mathrm{E}_{12}\right)$ & 0.245289 \\
\hline & & Communication and coordination $\left(\mathrm{E}_{13}\right)$ & 0.186095 \\
\hline & & Safety investment $\left(\mathrm{E}_{14}\right)$ & 0.107471 \\
\hline & & Rules and regulations $\left(\mathrm{E}_{15}\right)$ & 0.106117 \\
\hline & & Self-supervision $\left(\mathrm{E}_{16}\right)$ & 0.072875 \\
\hline \multirow{3}{*}{$\begin{array}{l}\text { Equipment and } \\
\text { facilities (E2) }\end{array}$} & \multirow{3}{*}{0.301383} & Sufficient equipment/facilities $\left(\mathrm{E}_{21}\right)$ & 0.542323 \\
\hline & & Equipment/facilities conditions $\left(\mathrm{E}_{22}\right)$ & 0.372413 \\
\hline & & Equipment/facilities performance $\left(\mathrm{E}_{23}\right)$ & 0.085264 \\
\hline \multirow{5}{*}{ Operations (E3) } & \multirow{5}{*}{0.313234} & Luggage safety operations $\left(\mathrm{E}_{31}\right)$ & 0.010947 \\
\hline & & Ordinary cargo safety operations $\left(E_{32}\right)$ & 0.09321 \\
\hline & & Dangerous goods acceptance $\left(\mathrm{E}_{33}\right)$ & 0.612948 \\
\hline & & Dangerous goods storage $\left(\mathrm{E}_{34}\right)$ & 0.164588 \\
\hline & & Dangerous goods loading $\left(\mathrm{E}_{35}\right)$ & 0.118306 \\
\hline \multirow{3}{*}{ Emergency (E4) } & \multirow{3}{*}{0.139187} & Emergency management plan $\left(\mathrm{E}_{41}\right)$ & 0.352677 \\
\hline & & Emergency-handling measures $\left(\mathrm{E}_{42}\right)$ & 0.50107 \\
\hline & & Emergency drilling plan $\left(\mathrm{E}_{43}\right)$ & 0.146253 \\
\hline \multirow{3}{*}{ Training (E5) } & \multirow{3}{*}{0.057365} & Training organization $\left(\mathrm{E}_{51}\right)$ & 0.640977 \\
\hline & & Training program $\left(\mathrm{E}_{52}\right)$ & 0.267794 \\
\hline & & Training quality control $\left(\mathrm{E}_{53}\right)$ & 0.091229 \\
\hline
\end{tabular}

\section{Case Study}

After establishing the safety assessment model for dangerous goods transport by air, we used an empirical study to examine the model stability. Many evaluation methodologies are available, such as the grey incidence analysis, artificial neural networks, and others [35]. The fuzzy set theory is suitable for risk assessment and has been adopted in many risk management studies [36]. The FSE method is a particularly useful tool to manage uncertainty and multiple attributes in group decision-making theories. FSE is defined by different fuzzy operators, which may produce different results even when using the same assessment model [37]. We used four fuzzy operators to test the stabilization of the model proposed in this paper.

We selected one mid-scale airline that has operated a dangerous goods transport business for over five years. Ten experienced experts ( $2 / 3$ of the 15 experts mentioned above) offered individual evaluations of the safety performance (actual state) of this airline according to the factors listed in Table 2. The evaluation was divided into two stages: in the first, experts reviewed all the relevant documents in the office; in the second, they observed the actual process/situation in the field. According to the factors listed in Table 2, 12 factors related to organization and regulation (E1), emergency (E4), and training (E5) were examined in the first stage. Taking $\mathrm{E}_{11}$ (organizational structure) as an example, we provided the experts with the organizational chart containing the department and divisions responsible for dangerous goods safety in this airline to facilitate the scoring process. Eight total factors spanning equipment and facilities (E2) and operations (E3) were evaluated in the second stage. Taking $E_{21}$ (sufficient equipment/facilities) for instance, the experts went to the warehouse and the ramp to determine whether the equipment and facilities of dangerous goods were adequate. 
The evaluation set consisted of $\mathrm{V}=$ \{excellent, good, ordinary, poor, bad $\}$. Taking $\mathrm{E}_{11}$ for example, after reviewing the organizational chart for dangerous goods safety of this airline, two of the 10 experts assigned a rating of "excellent"; four said "good"; three said "ordinary"; and one said "poor". Therefore, the evaluation results of $\mathrm{E}_{11}$ were $\{0.2,0.4,0.3,0.1,0\}$. The 20 factors were assigned individually, and results appear in Table 9.

Table 9. The evaluation values of the 20 factors.

\begin{tabular}{cccccc}
\hline Assessment Level & Excellent & Good & Ordinary & Poor & Bad \\
\hline $\mathrm{E}_{11}$ & 0.2 & 0.4 & 0.3 & 0.1 & 0 \\
$\mathrm{E}_{12}$ & 0.3 & 0.3 & 0.2 & 0.2 & 0 \\
$\mathrm{E}_{13}$ & 0.1 & 0.1 & 0.3 & 0.3 & 0.2 \\
$\mathrm{E}_{14}$ & 0.1 & 0.2 & 0.3 & 0.2 & 0.2 \\
$\mathrm{E}_{15}$ & 0.5 & 0.2 & 0.3 & 0 & 0 \\
$\mathrm{E}_{16}$ & 0.2 & 0.3 & 0.3 & 0.2 & 0 \\
$\mathrm{E}_{21}$ & 0.1 & 0.1 & 0.5 & 0.3 & 0 \\
$\mathrm{E}_{22}$ & 0.1 & 0.4 & 0.3 & 0.1 & 0.1 \\
$\mathrm{E}_{23}$ & 0.2 & 0.3 & 0.2 & 0.2 & 0.1 \\
$\mathrm{E}_{31}$ & 0.1 & 0.4 & 0.4 & 0.1 & 0 \\
$\mathrm{E}_{32}$ & 0.2 & 0.5 & 0.2 & 0.1 & 0 \\
$\mathrm{E}_{33}$ & 0.2 & 0.2 & 0.4 & 0.2 & 0 \\
$\mathrm{E}_{34}$ & 0.2 & 0.4 & 0.3 & 0.1 & 0 \\
$\mathrm{E}_{35}$ & 0 & 0.4 & 0.4 & 0.1 & 0.1 \\
$\mathrm{E}_{41}$ & 0.1 & 0.4 & 0.3 & 0.2 & 0 \\
$\mathrm{E}_{42}$ & 0.2 & 0.3 & 0.4 & 0.1 & 0 \\
$\mathrm{E}_{43}$ & 0.1 & 0.2 & 0.5 & 0.1 & 0.1 \\
$\mathrm{E}_{51}$ & 0.1 & 0.3 & 0.3 & 0.2 & 0.1 \\
$\mathrm{E}_{52}$ & 0.3 & 0.3 & 0.2 & 0.2 & 0 \\
$\mathrm{E}_{53}$ & 0 & 0.2 & 0.6 & 0.2 & 0 \\
\hline
\end{tabular}

The weights of the 5 drivers in Table 8 is denoted as vector W1; the weights of the 20 factors is denoted as vector W2; the assessment set in Table 8 is denoted as matrix $R$. Then the evaluation results $\mathrm{Q}$ can be calculated by

$$
Q=W 1^{T} \times R \times W 2
$$

In fuzzy evaluation, the commonly used operators include the minimum and maximum operator $(Z(\wedge, \vee))$, the multiplication and maximum operator $(Z(\bullet, \vee))$, the minimum and bounded operator $(Z(\wedge, \oplus))$, and the multiplication and bounded operator $(Z(\bullet, \oplus))[38,39]$. To compare the discrepancy of the evaluation results based on the AHP weights and comprehensive weights, eight evaluation results (Table 10) were calculated using four different fuzzy operators, respectively, according to Formula (9). Under the AHP weights, different operators produced different results: the evaluation results of the two operators were "good" and those of the other two operators were "ordinary". Under the weights revised by the entropy method, different operators had the same results ("ordinary" for all four operators). As such, the comprehensive weights demonstrated better weight stability than the AHP weights, and the model developed in this paper seems to be robust and reliable because the evaluation results did not vary by the operator. 
Table 10. The evaluation results of the different fuzzy operators.

\begin{tabular}{cccccccc}
\hline & Operator & Excellent & Good & Ordinary & Poor & Bad & Results \\
\hline & $Z(\wedge, \vee)$ & 0.1513 & 0.2987 & 0.2856 & 0.1707 & 0.0936 & Good \\
Fuzzy evaluation results of AHP weights & $Z(\bullet, \vee)$ & 0.1370 & 0.2960 & 0.3395 & 0.1762 & 0.0513 & Ordinary \\
& $Z(\wedge, \oplus)$ & 0.1778 & 0.2999 & 0.2858 & 0.1811 & 0.0555 & Good \\
& $Z(\bullet, \oplus)$ & 0.1670 & 0.2919 & 0.3325 & 0.1716 & 0.0370 & Ordinary \\
\hline \multirow{3}{*}{ Fuzzy evaluation results of AHP-entropy } & $Z(\wedge, \vee)$ & 0.1488 & 0.2403 & 0.3282 & 0.1878 & 0.0949 & Ordinary \\
weights & $Z(\bullet, \vee)$ & 0.1503 & 0.2354 & 0.3680 & 0.1985 & 0.0477 & Ordinary \\
& $Z(\wedge, \oplus)$ & 0.1747 & 0.2529 & 0.3174 & 0.1929 & 0.0622 & Ordinary \\
& $Z(\bullet, \oplus)$ & 0.1596 & 0.2710 & 0.3569 & 0.1782 & 0.0343 & Ordinary \\
\hline
\end{tabular}

The empirical results show that the efficiency and stability of the AHP-entropy method are better than that of AHP alone and the evaluation results are more scientific and reliable according to the model and algorithm established in this paper.

\section{Results and Discussion}

The model proposed in this paper aims to provide support for analyzing the safety factors of dangerous goods transport by air carriers. The 20 safety factors listed in Table 2, collected from a literature review and field experts' opinions, have three features. First, the factor system is comprehensive, incorporating safety assurance into human resources (organization, E1), finances (investment, E1), and infrastructure (equipment and facilities, E2) along with the safety promotion of professional operations (E3), emergency management (E4), and training (E5). This system is thorough and provides enhanced guidance to air carriers to improve managerial oversight related to dangerous goods. Second, although some factors such as $\mathrm{E}_{12}$ (quality control of outsourcing) and $\mathrm{E}_{14}$ (safety investment) were proposed and used in dangerous goods air transportation initially, the list of factors was examined twice by industry experts with different occupational backgrounds, all of whom pointed out that the factors are essential for the safety management of dangerous goods transport by air.

The weights reflect the importance of each driver and factor. Judging from the weight results in Table 5, the comprehensive priority of the five safety drivers are E3 $>$ E2 $>$ E1 $>$ E4 $>$ E5 . The comprehensive priorities of the five safety drivers are E3 $>$ E2 $>$ E1 $>$ E4 $>$ E5. In all cases, the importance (that is, weight) of E1, E2, and E3 were higher than E4 and E5, and operations (E3), with a weight of 0.313234 , was identified as the most important driver affecting the safety of dangerous goods transport by air. As such, dangerous goods operations should be prioritized first to guarantee safety, followed by equipment and facilities. The operation of dangerous goods air transportation not only involves accepting, storing, and loading declared dangerous goods according to the ICAO requirements, it also requires the identifying of undeclared dangerous goods from ordinary cargo and luggage to prevent potential risks, which may lead to more serious accidents and incidents [1]. In fact, it is difficult for air carriers to distinguish hidden dangerous goods from ordinary cargo and luggage without using security inspection machines, which has been a complicated proposition in China for quite some time.

The AHP weight, entropy weight, and comprehensive weight results for each factor are listed in Table 7. These three weights are subdivided by local weight (that is, the priority of each factor in its own driver) and global weight (that is, its relative importance among all 20 factors). By comparing the changes in global weights before and after revision using the entropy method, it is found that: (i) according to the global weight results calculated by the AHP method, the importance of each factor was nearly equally matched. The contribution of only one factor, $E_{21}$ (sufficient equipment/facilities), exceeded $10 \%$; the weight distributions of the other indices were balanced. The AHP method alone cannot determine the key activities on which air carriers should focus to ensure safety, especially when resources are limited. (ii) After revision by the entropy method, three factors had global contributions above $10 \%$ : dangerous goods acceptance $\left(\mathrm{E}_{33}\right)$, sufficient equipment/facilities 
$\left(E_{21}\right)$, and equipment/facility conditions $\left(E_{22}\right)$. The global weight of each was $19.2 \%, 16.3 \%$, and $11.2 \%$, respectively, accounting for $46.8 \%$ of the total. In other words, along with sufficient equipment/facilities, air carriers should also focus on regulating dangerous goods acceptance and equipment/facility conditions. These three aspects collectively determine the safety and sustainability of the transport of dangerous goods by air. Therefore, after revising the AHP method via the entropy method, the obtained weight set is more scientific and has practical value for industry work.

Dangerous goods acceptance $\left(E_{33}\right)$ was found to be the most important factor affecting the safety of dangerous goods transport by air as revealed in Table 7. Du [40] indicated that acceptance is an essential component of the safe transport of dangerous goods. In our research, we found dangerous goods acceptance to be the most important factor among the 20 factors. The main task of the dangerous goods acceptance for air carriers is verifying the regulatory compliance, including the classification, packaging, marking, labeling, and all associated documents, a task that is completed by the shipper or cargo agent. Dangerous goods acceptance transfers risk from the shipper or cargo agent to the carrier. In the event of an incomplete investigation during the dangerous goods acceptance procedure, the carrier is held accountable even if either the shipper or cargo agent is at fault [25]. Therefore, a specialized team of air carriers is often responsible for dangerous goods acceptance in actual operations.

Equipment and facilities (E2) were found to have high priority as indicated in Tables 5 and 7. The equipment and facilities for dangerous goods transport by air include, but are not limited to specialized warehouses, storage racks, unit load devices, forklift trucks, safety defense equipment, inspection equipment, and so on. They constitute the essential hardware to ensure the proper handling of dangerous goods. Compared to the performance $\left(E_{23}\right)$ of equipment/facilities, sufficiency $\left(\mathrm{E}_{21}\right.$; global weight $\left.=16.3 \%\right)$ and conditions $\left(\mathrm{E}_{22} ;\right.$ global weight $\left.=11.2 \%\right)$ take precedence. Air carriers are encouraged to maintain and upgrade equipment and facilities in a timely manner to minimize the potential risks associated with damage and degradation.

The weights of the drivers and factors in Tables 5 and 7 were calculated with AHP and the entropy method based on a pair-wise comparison of the relative importance of each driver and factor, judged by 15 Chinese experts using a 9-point scale. Therefore, the findings of the key drivers and factors detailed herein are highly relevant to the actual conditions in China. Although the data in Table 5 show that dangerous goods operations (E3) and equipment/facilities (E2) are key drivers behind the safety performance of air carriers in China, organization and regulations (E1), emergency (E4), and training (E5) cannot be ignored. Rather, the management, organization, and training surrounding dangerous goods constitute strong and indispensable support for the infrastructure and operations business in China. Without organization and training, any infrastructure, operations, and emergency handling of dangerous goods are impossible.

We kept international applicability in mind during this study, including refining safety factors from the literature when choosing an empirical case. The 20 factors summarized in Table 2 were adopted from previous studies conducted around the world or from ICAO international regulations, indicating that these factors are suitable for dangerous goods transport by air in China as well as in other countries. Additionally, while the model investigated in this paper depended partly on the judgment of Chinese experts and revealed some key drivers and factors useful for the development of risk control measures in China, the 20 safety factors identified can also be used to assess the safety situations regarding dangerous goods air transport of air carriers around the world. The assessment model was verified using a case analysis combined with the FSE method. When selecting a mid-scale airline as an empirical case, the representativeness and typicality were emphasized. The case study indicates that the model obtains reliable assessment results: the findings show that the evaluation results acquired through the AHP-entropy method are more stable than those calculated by the AHP method. The proposed method is also more efficient and reasonable in identifying air carrier safety levels. Therefore, the safety assessment model proposed in this paper is reliable and has good feasibility and practicality for dangerous goods transport by air carriers. 


\section{Conclusions}

In contrast to road, railway, and marine transport methods, air transport is more international and the goods it carries are of higher universal value. The impact scope of the occurrence of accidents and incidents involving dangerous goods is wider and the consequences are even worse than with other modes of transportation. The transport safety of dangerous goods is an important aspect of aviation safety. China plays an important role in the chain of dangerous goods air transportation. Shipping dangerous goods is one of the most complex airline tasks, requiring careful safety measures and transportation technologies. Therefore, studies concerning the safety management of dangerous goods air transportation are necessary.

The main contributions of the paper are summarized below:

(i) Based on a literature review and interviews with industry experts, a novel index system was established to assess the safety of dangerous goods transport activities by air carriers, including 20 factors related to organization and regulations, equipment and facilities, operations, emergency, and training. Compared with other studies on dangerous goods air transportation [14-17,40], the factors proposed in this paper focus on the risks air transport enterprises can control to achieve safer, greener sustainable development, reflecting the comprehensive safety status of air carriers.

(ii) AHP and entropy methods were used jointly to determine factor weights. By comparing the changes in factor weights before and after the entropy revision, the proposed method appears to reconcile the influence of subjective preferences from AHP method experts and objective data deviation in the entropy method. The weights were also more scientific in reflecting the important safety factors related to dangerous goods air transportation and hence can guide air carrier management.

(iii) A case study was used to apply an FSE method to the model. The combined method for weight assignment proved to be stable. To our knowledge, this study is the first to apply a combined qualitative and quantitative approach to study the safety assessment of dangerous goods transport by air carriers. Its findings provide ways to differentiate risk factors in dangerous goods transport and enrich the application of safety evaluation techniques.

(iv) The findings reveal that for operations and infrastructure, especially in terms of dangerous goods acceptance, the sufficiency and condition of infrastructure are the most important factors affecting the safety performance of dangerous goods air transportation in China. The results provide a suggested scheme for air carrier resource allocation to achieve better safety performance and sustainable development.

A number of future research directions could be pursued from this study. Some factors identified in this paper had been previously incorporated into safety studies on dangerous goods air transport while others had not. The newly introduced factors were drawn from two sources: literature related to other transport modes (that is, metro railway) and expert opinion. Although all factors were further reviewed by 15 experts who were experienced and had worked in dangerous goods air transportation for over 10 years, some factors affecting the safety of air carrier transport may have been overlooked. As such, additional research is warranted to examine the factors affecting the safety of dangerous goods air transportation.

Author Contributions: The author Hongli Zhao drafted the manuscript. Ning Zhang and Yu Guan contributed to the research methodology and polished the language.

Acknowledgments: This research was supported by the Security Capacity Construction Foundation of Civil Aviation Authority of China (Project Number: 14000900100016J013). The authors would like to acknowledge the experts who participated in the study and those who provided suggestions.

Conflicts of Interest: The authors declare no conflict of interest. 


\section{References}

1. Ellis, J. Undeclared dangerous goods-Risk implications for maritime transport. WMU J. Marit. Aff. 2010, 9, 5-27. [CrossRef]

2. Forigua, J.; Lyons, L. Safety analysis of transportation chain for dangerous goods: A case study in Colombia. Transp. Res. Procedia 2016, 12, 842-850. [CrossRef]

3. 1001 Crash. Asiana Cargo-Boeing 747-48EF off Jeju, South Korea, 28 July 2011. 2015. Available online: http: / / www.1001crash.com/index-page-description-accident-Asiana_B747-lg-2-crash-299.html (accessed on 24 August 2016).

4. Fabiano, B.; Currò, F.; Palazzi, E.; Pastorinov, R.A. framework for risk assessment and decision-making strategies in dangerous good transportation. J. Hazard. Mater. 2002, 93, 1-15. [CrossRef]

5. Torretta, V.; Rada, E.C.; Schiavon, M.; Viotti, P. Decision support systems for assessing risks involved in transporting hazardous materials: A review. Saf. Sci. 2017, 92, 1-9. [CrossRef]

6. Conca, A.; Ridella, C.; Sapori, E. A risk assessment for road transportation of dangerous goods: A routing solution. Transp. Res. Procedia 2016, 14, 2890-2899. [CrossRef]

7. Gheorghe, A.V.; Birchmeier, J.; Vamanu, D.; Papazoglou, I.; Kroger, W. Comprehensive risk assessment for rail transportation of dangerous goods: A validated platform for decision support. Reliab. Eng. Syst. Saf. 2005, 88, 247-272. [CrossRef]

8. Batarliene, N.; Jarasuniene, A. Analysis of the accidents and incidents occurring during the transportation of dangerous goods by railway transport. Transport 2014, 29, 395-400. [CrossRef]

9. Ellis, J. Analysis of accidents and incidents occurring during transport of packaged dangerous goods by sea. Saf. Sci. 2011, 49, 1231-1237. [CrossRef]

10. Verma, M.; Verter, V. Railroad transportation of dangerous goods: Population exposure to airborne toxins. Comp. Oper. Res. 2007, 34, 1287-1303. [CrossRef]

11. Molero, G.M.; Santarremigia, F.E.; Aragonés-Beltrán, P.; Pastor-Ferrando, J.P. Total Safety by design: Increased safety and operability of supply chain of inland terminals for containers with dangerous goods. Saf. Sci. 2017, 100, 168-182. [CrossRef]

12. Chen, J.; Wen, C. Risk assessment model approach for dangerous goods transported by railway. J. Transp. Secur. 2011, 4, 351-359. [CrossRef]

13. Benekos, I.; Diamantidis, D. On risk assessment and risk acceptance of dangerous goods transportation through road tunnels in Greece. Saf. Sci. 2017, 91, 1-10. [CrossRef]

14. Hsu, W.K.K.; Huang, S.H.S.; Tseng, W.J. Evaluating the risk of operational safety for dangerous goods in airfreights-A revised risk matrix based on fuzzy AHP. Transp. Res. Part D 2016, 48, 235-247. [CrossRef]

15. Chang, Y.H.; Yeh, C.H.; Liu, Y.L. Prioritizing Management issues of moving dangerous goods by air transport. J. Air Transp. Manag. 2006, 12, 191-196. [CrossRef]

16. Du, W.B. Risk Analysis and Control Method of Dangerous Goods Air Transportation of Some Company. Master's Dissertation, Fudan University, Shanghai, China, 2010. (In Chinese)

17. Yang, W. Research on Vulnerability Assessment of Ground Emergency System in Air Transport of Dangerous Goods. Master's Dissertation, Civil Aviation University of China, Tianjin, China, 2015. (In Chinese)

18. Civil Aviation Authority of China. The Annual Report of Dangerous Goods Air Transport in China of the Year 2016. Available online: http://www.caacdgc.org/tzgg/zhxw/201705/t20170527_6390.html (accessed on 12 December 2017).

19. $\mathrm{Xu}, \mathrm{J}$. Analysis and control measures for unsafe events in air transportation of dangerous goods. China Civ. Aviat. 2016, 4, 31-32. (In Chinese)

20. Chen, W.; Li, J. Safety performance monitoring and measurement of civil aviation unit. J. Air Transp. Manag. 2016, 57, 228-233. [CrossRef]

21. International Civil Aviation Organization. Annex 19 to the Convention on International Civil Aviation: Safety Management; International Civil Aviation Organization: Montreal, QC, Canada, 2016.

22. Shyur, H.J. A quantitative model for aviation safety risk assessment. Comput. Ind. Eng. 2008, 54, 34-44. [CrossRef]

23. Kyriakidis, M.; Hirsch, R.; Majumdar, A. Metro Railway safety: An analysis of accident precursors. Saf. Sci. 2012, 50, 1535-1548. [CrossRef] 
24. International Civil Aviation Organization. Annex 18 to the Convention on International Civil Aviation: The Safe Transport of Dangerous Goods by Air; International Civil Aviation Organization: Montreal, QC, Canada, 2016.

25. International Civil Aviation Organization. Technical Instructions for the Safe Transport of Dangerous Goods by Air (Doc 9284), version 2017-2018; International Civil Aviation Organization: Montreal, QC, Canada, 2017.

26. Song, L.L.; Li, Q.M.; George, F.L.; Deng, Y.L.; Lu, P. Using an AHP-ISM Based Method to study the vulnerability factors of urban rail transit system. Sustainability 2017, 9, 1065. [CrossRef]

27. Chen, T.; Jin, Y.Y.; Qiu, X.P.; Chen, X. A hybrid fuzzy evaluation method for safety assessment of food-waste feed based on entropy and the analytic hierarchy process methods. Expert Syst. Appl. 2014, 41, 7328-7337. [CrossRef]

28. Shannon, C.E. A mathematical theory of communication. Bell Syst. Tech. J. 1948, 27, 379-423. [CrossRef]

29. Huang, W.Z. AHP method on the weight of entropy and its application in ship investment decision making. J. Shanghai Marit. Univ. 2000, 21, 97-101. (In Chinese)

30. Xie, C.S.; Dong, D.P.; Hua, S.P.; Xu, X.; Chen, Y.J. Safety evaluation of smart grid based on AHP-entropy method. Syst. Eng. Proceida 2012, 4, 203-209.

31. Wang, T. The Research of electronic banking risk evaluation based on comprehensive assessment AHP-entropy. Int. J. Sci. Technol. 2014, 7, 413-422. [CrossRef]

32. Wu, G.D.; Duan, K.F.; Zuo, J.; Zhao, X.B.; Tang, D.Z. Integrated sustainability assessment of Public Rental Housing Community Based on a Hybrid Method of AHP-Entropy Weight and Cloud Model. Sustainability 2017, 9, 603. [CrossRef]

33. Saaty, T.L. An exposition of the AHP in reply to the paper 'Remarks on the analytic hierarchy process'. Manag. Sci. 1990, 36, 259-268. [CrossRef]

34. Zou, Z.H.; Yun, Y.; Sun, J.N. Entropy method for determination of weight of evaluating indicators in fuzzy synthetic evaluation for water quality assessment. J. Environ. Sci. 2006, 18, 1020-1023. [CrossRef]

35. Peng, Z.L.; Zhang, Q.; Yang, S.L. Overview of comprehensive evaluation theory and methodology. Chin. J. Manag. Sci. 2015, 11, 245-256. (In Chinese)

36. Zhao, X.B.; Hwang, B.G.; Gao, Y. A fuzzy synthetic evaluation approach for risk assessment: A case of Singapore's green projects. J. Clean. Prod. 2016, 115, 203-213. [CrossRef]

37. Suer, G.A.; Arikan, F.; Babayigit, C. Effects of different fuzzy operators on fuzzy bi-objective cell loading problem in labor-intensive manufacturing cells. Comput. Ind. Eng. 2009, 56, 476-488. [CrossRef]

38. Liu, Y.T.; Hu, J.B. A mathematical model and its parameters estimation for fuzzy evaluation. J. Beijing Polytech. Univ. 2001, 3, 112-115. (In Chinese)

39. Shen, J.H.; Fu, X.Y.; Zhao, Y.X. Improvement of the Fuzzy Comprehensive Evaluation Model. Fuzzy Syst. Math. 2011, 6, 127-132. (In Chinese)

40. Du, J. Research on the Risk Evaluation Index System for Collection in Air Transport of Dangerous Goods. Saf. Environ. Eng. 2012, 5, 77-79. (In Chinese) 